\title{
Research on Economic Law Protection of Telecom Consumer Rights
}

\author{
Deyu Liu $^{1, \text { a }}$ \\ ${ }^{1}$ Tianjin University, Tianjin, 300072, China \\ ${ }^{\mathrm{a}}$ email
}

Keywords: Economic law, Law protection, Telecom consumer rights

\begin{abstract}
The strong professionalism of telecom industry and the market monopoly status of telecom operators determine that the rights and interests of telecom consumers are inevitably limited and infringed. At present, China's economic law for telecommunications consumers rights protection has many deficiencies. This paper puts forward some countermeasures for the protection of telecom consumers' economic law, including establishing special laws, clarifying relative concepts and strengthening law enforcement to provide some references for the relative researchers.
\end{abstract}

\section{Introduction}

In the economic law of freedom, justice, security and the interests of the whole society values are all reflected in maintaining the interests of consumers, is the relationship between the market economy the overall interests of the vulnerable groups of consumers simply point on the surface. The combination of the protection of consumer rights and the value of economic law is highlighted in the protection of the weak. Because of the problems in the economic activities such as the existence of asymmetric information, consumers are the vulnerable groups in economic activities, the law should give them special protection, which is China's current law and the whole society pay more attention to the problem. The consumer is a social problem, and the realization mechanism of its benefits has become a remarkable standard for considering the progress of market economy in various countries. The rights and interests of consumers to achieve and maintain the interests of the whole society is based on the consideration of value, social fairness and justice is the embodiment of the value, the perfect security of economic law and freedom value to protect consumers' rights and interests' mechanism analysis and system setting, maintenance problems in a certain extent to solve the rights and interests of consumers. On the other hand, the maintenance of the rights and interests of consumers shows the value of economic law. This ought to be law theory plays a great practical role in judicial practice. China Telecom industry monopoly is very serious, even the relevant laws and regulations cannot restrain the monopoly of the telecommunications industry. At present, many problems in the telecommunications industry will inevitably affect the development of the telecommunications industry. In the future, these problems will become a stumbling block. In the laws and regulations, there is no clearly standardized and unified management of the telecommunications industry, which led to confusion in the telecommunications industry market. Generally speaking, consumers are dissatisfied with the service in the telecom industry, and the rights and interests of consumers are not guaranteed in the telecom industry.

\section{Shortcomings of Economic Law Protection of Telecom Consumer Rights}

Absent Special Legislation. At present, the laws of protecting the rights of Telecom consumers in China are concentrated in the law on the protection of consumers' rights and interests, the criminal law and regulations and regulations and documents of various departments. For example, the Ministry issued the "Regulations" telecommunications and Internet users' personal information protection, prohibition of telecommunications and Internet companies to release Chen user information. Yes, there are still instances of leaked user information, and consumer rights have been violated. However, our country has promulgated a series of laws and regulations to protect consumer rights, but the result is very little. The reason is that our telecom enterprises monopolize the whole 
nation's telecommunication service. A monopoly caused between telecom enterprises and consumers of telecommunications strength, consumers are in a relatively passive position, accepted by the telecom enterprises transfer to their own information passively, it is often difficult to distinguish between true and false, often to the detriment of the consumer's right to know, to the past is difficult to safeguard the legitimate rights and interests. On the other hand, the for-profit telecommunication enterprises, tend to ignore the needs of consumers and choose the most suitable scheme, which makes consumers rights is inevitable in the process of the telecommunications business profit in violation of China telecom industry, China has not yet unified legislation, has not issued the "telecommunications law only. A" Telecommunications Regulations "and related regulations, laws and regulations for telecommunications consumer protection are scattered, the lack of a comprehensive and systematic protection of the legislative problems. China's Telecommunications Regulations, most of the provisions of the overall industry order based, telecommunications consumer protection content is not much, in the "criminal law" into the sentence, the need to achieve serious standards. Therefore, China's laws and regulations on the protection of telecommunications consumers is very fragmented, and the protection of the intensity is very inadequate.

Unclear Basic Concept. Although the law of the protection of consumer rights and interests has been adopted to protect all consumers, the consumer protection law has been promulgated for more than twenty years. Although it has been revised two times, it has not substantially expanded and refined the content of the rights and interests of consumers. With the development of computer network and communication satellite technology, the connotation and extension of the rights and interests of consumers have undergone breakthrough development and innovation. The hysteresis of consumer protection law has been quite obvious. It has strong technical and complex professional industry for the telecommunications industry, its operating mode, trading rules, contracting habits, compliance procedures, contrast and market position between consumers and business operators have obvious particularity, has since become the necessity and possibility of the system. If Telecom consumers are included in the scope of protection of the consumer protection law, it is tantamount to abandoning the protection of the rights and interests of telecom consumers. Therefore, it is necessary to separate the concept of Telecom consumers from the concept of general consumers and give them specific and special protection. Unfortunately, at present, telecom consumers in China are not a legal concept, nor have they become a specific concept because of the widespread recognition of the academic community. Many developed countries in the telecom market in the world have already isolated Telecom consumers from the general consumers, and have made special protection to them in terms of industry characteristics, which is worth our country's reference. In the United States, the bill notes that the law aims at promoting competition and deregulation to ensure that telecom consumers enjoy higher quality telecommunications services at lower prices. Around the legislative intention of protecting the interests of Telecom consumers, the concept of Telecom consumers is undoubtedly the core word of the American Telecommunications law. Therefore, it can be said that the United States Telecom Law reaffirms the concept and legal status of telecom consumers.

Loose Enforcement Degree. The provisions of China's "anti-monopoly law", market dominance refers to one or more enterprises have to dominate a particular market certain power, the power can make the competition mechanism constraints, and can have a significant impact on the market. China's Anti-Monopoly Law lists six factors that determine the market dominance, including the market share of the operator, the ability of the operator to control the market or the raw material purchasing market. According to the principle of "who advocates the burden of proof" in the civil lawsuit, the plaintiff bears the burden of proof. Ordinary consumers simply cannot collect data related to Netcom's ability to control the market, and Netcom as a defendant cannot help the plaintiff to provide relevant data. The ruling revealed the difficulty of safeguarding the rights of consumers in the face of monopoly industries. Although the case ended in a lawsuit against consumers, we should cast aside the form of the result of the lawsuit and analyze the infringement of the substantive rights involved in the case itself. Netcom has attached many unreasonable conditions in its services to consumers, and excluded the plaintiff from a specific service area. It is a discriminatory treatment, which infringes the consumer's right of independent choice. China's consumer rights protection act 
and the telecommunications service standard respectively establish the consumer's right of independent choice from the point of view of consumers and operators. However, the two laws do not stipulate the responsibility, consequences and remedies for consumers' right to choose themselves, so that consumers can enjoy the essential content of the right although they have the right. In this case, the plaintiff's right of independent choice has been infringed, but the result of safeguarding rights has not been realized, which indicates the awkward position of the right of independent choice.

\section{Suggestions of Economic Law Protection of Telecom Consumer Rights}

Establish Special Laws. From the analysis of consumers to choose the right protection point of view, the general principles of the civil law and the contract law is the general law, due to the establishment of the principle of too much emphasis on the general, cannot effectively solve various problems arising in the field of telecommunications; anti unfair competition law is only indirectly involved in independent consumer choice. As a special consumer protection law to protect the interests of consumers, only enumeration mode is adopted for the relevant rights, a simple list, lack of more specific protection, leading to consumers right to choose cannot be protected. From the telecommunications regulatory legislation, although the legislation is more, but in the content, are focused on the National Security Telecommunications and related business applications, telecommunications provisions relating to the protection of consumer rights, a few words, to meet the actual needs. According to the characteristics of the telecom service is highly professional technology complex, the telecom consumers choose the connotation and extension of the right to make a clear definition, because consumers are at a disadvantage that telecom service information, legislation should be forced to explain to the telecom operators in the specific information and the obligation of explanation. Clearly infringe consumer the right to choose the responsibility for the consequences, the responsibility for the consequences should be sufficient to enable consumers to actively get effective compensation to encourage consumer rights, consumer protection law to make up for the current price of two times the amount of compensation for the lack of. The current consumer protection law on the right to choose, only the provisions of the authenticity of the operators to provide information, does not require the operators to provide adequate information adequacy and timeliness, the big gap needs to be made up in the future legislation. In view of current relevant legislation of telecommunications consumer protection with low level, scattered layout, simple terms and other defects, we can learn from the practice of the United States, making special laws to protect telecommunications unified telecommunications of the interests of consumers.

Clarify Relative Concepts. The content of the right of choice essentially contains two aspects: one is subjective voluntary; the other two is objective freedom. First, subjective aspects of voluntariness. Voluntary is from the subjective aspects of consumers, emphasizing that consumer behavior is based on subjective voluntary choice results. According to the principle of civil law, one of the effective elements of civil action is that the meaning of the party is true and the act of expressing the real intention does not produce the consequences of civil juristic act. Second, the objective freedom. The so-called objective freedom, that is, without interference from others, coercion, coercion, deception and other illegal interference. The exercise of consumer's right of independent choice is influenced by its own judgment ability, information screening ability and many external factors. Therefore, the author from the subjective and objective two aspects will be defined as: consumers right to choose according to their actual needs, starting from their own subjective desire, in the absence of the operator or other market players, induced by stress, fraud, concealment and other improper interference, free to choose a right kind of commodity or service provider and the goods or services. Under the market economy condition, the right of independent choice is not only the basic guarantee for the material interests of consumers, but also the respect and protection of the spiritual benefits of consumers' personal dignity, which is the symbol of social civilization. China's consumer protection law clearly stipulates that consumers enjoy the right to choose their own goods or services. It is difficult to find loopholes and problems. In order to improve and perfect the law, the 
rights and interests of consumers should be taken into consideration, and should be taken into consideration. Only in this way can we promote the development of telecommunications.

Strengthen Law Enforcement. Telecom operators' business registration is generally in the big city, but the majority of the rural consumers, the consumers in remote areas when they need to protect their rights to the remote operator rights, and safeguarding the legitimate rights and interests of different local rights compared to the cost of the cost of time and money costs are much higher, including transportation accommodation all necessary expenses necessary. In fact, in the telecommunications service dispute rights, small target and high cost of rights of consumers often make different litigation rights of the loss outweighs the gain., the difficult Telecom consumers is tantamount to one disaster after another. The plaintiff has become a great institutional obstacle in defending the rights of Telecom consumers who are in a disadvantageous position on the defendant's traditional jurisdiction rules. The plaintiff's jurisdiction principle applies to the field of Telecom consumer disputes, and there are many disadvantages which are not conducive to dispute resolution. The rules of jurisdiction over consumer disputes abroad are worthy of our reference. The provisions of the European mainland Brussels jurisdiction on civil cases and the execution of the judgment of the Convention, the general sales of goods and services of the contract, as long as the consumer meets the following two conditions, consumers have the right to choose their own domicile or the domicile of the proceedings: the conclusion of the contract the former had specifically issued an invitation or to consumers advertising; consumer contract in order to implement the necessary actions in the country to cooperate. China is still not conducive to the principle of jurisdiction of consumers, abuses are frequent in order to better protect the rights and interests of consumers. In the revision of the civil procedure law, it is necessary to change the traditional practice and allow consumers to lodge lawsuits in their places of residence when disputes arise.

\section{Conclusion}

For a variety of reasons, the telecommunications industry has become a monopoly industry. This prevents the rights and interests of consumers and hinders the development of the telecommunications industry. Therefore, we should establish and perfect the legal system, safeguard the rights and interests of consumers and promote the development of the telecommunications industry.

\section{References}

[1] Zhang Xinbao, Ge Xin. Comprehensive Handling of Telecommunication Fraud on Personal Information Protection [J]. Journal of the Party School of the Central Committee of the CPC, 2016, 20(5): 42-49.

[2] Bai Jinya, Shi Yanliang. Research on Protection of Consumer'S Right to Know in The Public Service Contracts [J]. Tianjin Legal Science, 2016(4): 52-58.

[3] Nie Yue. Investigation and Analysis on the Protection of Consumer Rights and Interests of College Students Taking College Students in Qinghai Province as an Example [J]. Journal of Hubei Correspondence University, 2016, 29(6): 33-34.

[4] Chai Weiwei. Research on Legal Protection of Telecom Consumers’ Right to Choose [J]. Hebei Law Science, 2015, 33(6): 77-85. 